\title{
The Relationship Between Internet Use and Mental Health Among Older Adults in China: The Mediating Role of Physical Exercise
}

\author{
Sheng Zhang ${ }^{1,2}$ \\ Yujie Zhang ${ }^{2}$ \\ 'China Institute for Urban Governance, \\ Shanghai Jiao Tong University, Shanghai, \\ 200030, People's Republic of China; \\ ${ }^{2}$ School of International and Public \\ Affairs, Shanghai Jiao Tong University, \\ Shanghai, 200030, People's Republic of \\ China
}

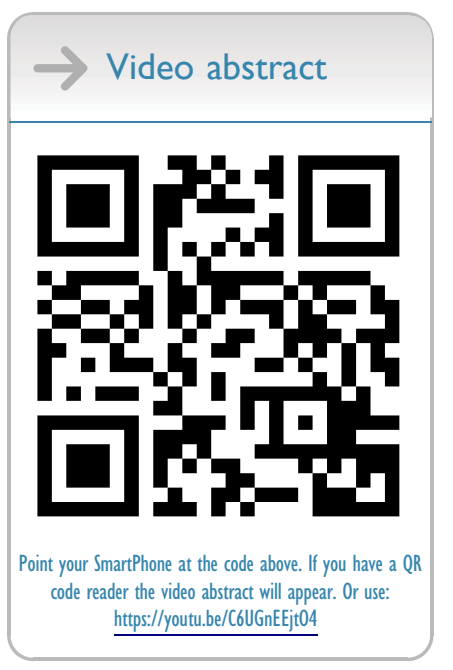

Correspondence: Yujie Zhang School of International and Public Affairs, Shanghai Jiao Tong University, 1954 Huashan Road, Xuhui District, Shanghai, 200030, People's Republic of China Tel +86-186-9696-0193

Email zhangyujie@situ.edu.cn
Objective: Affected by internet applications, mental health among older adults has become an important public health issue in China. This study aimed to use cross-sectional data to explore how internet use affects mental health among older adults in China, along with the moderating role of physical exercise in the above relationship.

Methods: This study employed data from the Chinese General Social Survey (CGSS) conducted in 2017. In addition, OLS regression was adopted to explore the impacts of internet use on the mental health of older adults in China.

Results: Results from the cross-sectional data model showed that internet use had a statistically significant and positive correlation with the mental health of older adults. The regression result of the full sample showed that the regression coefficient of the influence of internet use on the mental health of the elderly was 0.114 , which was significant at the $1 \%$ level. Furthermore, this study used mediating analysis to explore the possible underlying mechanism by which internet use influenced mental health status through physical exercise. Physical exercise played a mediating role in the relationship between internet use and mental health; the ratio of the indirect effect to total effect mediated was 0.272 . It is important to note that the effect size of the indirect effect through physical exercise was quite large.

Conclusion: Our findings suggested that internet use was significantly associated with better mental health status for older Chinese residents, mediated by higher physical exercise frequency, which was consistent with China's recent efforts to promote health governance with the "Internet Plus Exercise" campaign. Consequently, the government must encourage the development of more internet applications suitable for the elderly to increase their exercise frequency and ultimately improve their mental health. These results also provided insights for clinical solutions.

Keywords: internet use, mental health, physical exercise, older adults, health governance

\section{Introduction}

The elderly in China is a subject worthy of attention in an aging society, and their mental health problems have created many challenges in the 21 st century with regard to health management. ${ }^{1}$ How to improve the mental health status of older adults has become the focus of recent research. ${ }^{2}$ Moreover, the mental health of the elderly has become an important public health issue in China. By the end of 2019, Chinese older adults aged over 65 had reached 176 million in number, accounting for $12.57 \%$ of the country's total population. With the increasing trend of population aging, attention to the mental health of the elderly was a sign of social progress. The Outline of Healthy 
China 2030 Plan pointed out that population aging was an important challenge affecting national health governance. Therefore, from the perspective of mental health management, the elderly were encouraged to use digital devices and the internet to improve both their physical and mental health statuses.

The accelerated development of China's internet penetration provided a new way to influence the mental health of the elderly population. ${ }^{3}$ Compared to traditional offline means of influencing the mental health of older adults, the internet created a more diversified, convenient, personalized, and innovative mental health protection channel by generating a massive flow of information to enrich the inner worlds of older adults and, thus, improve their mental health status. ${ }^{4-6}$ The Chinese government issued The Implementation Plan on Effectively Solving the Difficulties of the Older Adults in Using Intelligent Technology in November 2020. It was proposed that by the end of 2022, intelligent services for older adults should be significantly improved, and the convenience of smart facilities should be continuously modified, to establish a long-term mechanism that lets the elderly use more intelligent facilities and internet applications. The release of the implementation plan has further strengthened the government's attention on combining the internet with regular health management measures of the elderly and highlighting the importance and necessity of internet technology application development in the mental health of older adults.

Based on Grossman's health theory, internet use has an impact on the psychology of older adults, and internet technology enhances health capital by meeting older adults' personalized needs regarding mental health. ${ }^{7,8}$ Combined with the health theory, previous studies proved that people would use the internet to make personalized choices to improve their mental health status. ${ }^{9-14}$ This theoretical view can also explain how the elderly in China use the internet to improve their mental health by meeting their personalized needs, such as communication with friends, professional medical counseling, and health surveillance, to enhance their health capital.

Previous studies have explored the impact of internet use on mental health among older adults. Earlier studies found that the use of the internet by older adults was a trend and a unique way to pursue mental health improvement. $^{15-20}$ Furthermore, some studies indicated that the use of the internet could promote the mental health of older adults by motivating them to lead healthier lifestyles and engage in more social activities. ${ }^{21-25}$ Some empirical studies showed that a high level of internet use was positively associated with a high level of mental health status among older adults. ${ }^{26-31}$ Moreover, a study argued that in the virtual world, older adults could have a sense of psychological satisfaction and a greater sense of belonging to society, thereby improving their inner happiness and mental health. ${ }^{32}$ The study of Hunsaker and Hargittai (2018) supported this conclusion; the researchers agreed that the internet helps the elderly obtain a kind of spiritual pleasure, which is beneficial to their mental health. ${ }^{33}$ A study in China also found that the internet kept older adults in close contact with society, so they were less prone to depression. ${ }^{34}$ In addition, some studies summarized the mediating role of social capital between internet use and the mental health of older adults. ${ }^{35,36}$ Several studies revealed that internet application capability, ${ }^{37}$ internet accessibility, ${ }^{38}$ income level, ${ }^{39}$ social class, ${ }^{40}$ family support, ${ }^{41}$ and other factors could also affect the mental health of older adults when they used the internet.

Overall, while previous studies have confirmed that internet use has a significant impact on the mental health of older adults, ${ }^{42,43}$ few studies have investigated the underlying mediating mechanisms through which internet use affects mental health. Furthermore, existing studies have confirmed the ability of the internet to enhance exercise, such as making physical training plans, ${ }^{44}$ improving the consciousness of exercise, ${ }^{45}$ optimizing exercise methods, ${ }^{46}$ evaluating exercise results, ${ }^{47}$ and other improvement strategies. In a sense, the internet encourages people to exercise, and active exercise will further affect people's mental health. In addition, in the context of China's "Internet Plus Exercise" campaign, which was emphasized again in the National Fitness Plan (20212025) recently issued by China's State Council, Chinese government has paid special attention to providing intelligent services for national fitness, such as promoting virtual sports. How to promote the continuous transformation and upgrading of the "Internet Plus Exercise" campaign has become the focus of China's public health policy. With the development of technology, "Internet Plus Exercise" has already been integrated into every aspect of production and life. Moreover, during the COVID-19 outbreak, the "Internet Plus Exercise" policy gained more attention as most people had to stay at home and do virtual sports. In early 2021, China's State Sports General Administration launched the pilot of a smart community fitness center in 7 
places nationwide, hoping to accelerate the deep integration of "Internet Plus Exercise" and national fitness. In view of this, it is worth exploring how internet use affects the mental health of older adults, ${ }^{48}$ with a particular focus on the mediating role of physical exercise. To fill this research gap, this study used survey data to explore how internet use affects mental health among older adults in China and the underlying mediating mechanism. The results of this study could provide a deep understanding of how internet use affects mental health among older adults.

\section{Methods \\ Data Source}

The cross-sectional data of this study was obtained from the 2017 wave of the Chinese General Social Survey (CGSS: http://cnsda.ruc.edu.cn/index.php?r=projects/view andid=94525591). The CGSS was conducted by the Department of Sociology, Renmin University of China and the Department of Social Sciences, City University of Hong Kong, focusing on the evolution of China's social structure. The stratified 4-stage probability sampling method was used in the survey, which was carried out in 22 provinces, 4 autonomous regions, and 4 municipalities; the population of 2798 districts and counties (excluding Tibet Autonomous Region, Hong Kong, Macao, and Taiwan) was the overall population of the survey, which was representative and was the authoritative data with scientific research value. The actual sample size of this project was 12,582. The subjects of this study were the elderly population over 60 years old. After the screening and elimination of samples lacking relevant variables, 1674 effective samples were obtained.

Because the present study was conducted based on the de-identified, publicly available CGSS data, it does not constitute human subject research. Its institutional review board review was waived because there was no interaction with any individual, and no identifiable private information was used.

\section{Variables}

\section{Dependent Variable}

In this study, we used subjective psychological well-being to represent the mental health status of the elderly. ${ }^{49}$ Mental health means that all aspects of psychology and activity process are in a good or normal state. The ideal state of mental health is to keep a good character, normal intelligence, correct cognition, appropriate emotion, reasonable will, positive attitude, appropriate behavior, and good adaptation. ${ }^{50-52}$ Subjective mental health refers to the overall evaluation of the evaluator's quality of life according to their own standards. ${ }^{53}$ At present, more researchers are using subjective mental health as an important index of mental health. The level of subjective mental health is related to mental health. ${ }^{54,55}$ Through the discussion of the relationship between subjective mental health and mental health, previous studies provide a certain theoretical and factual basis for improving people's quality of life and promoting the development of physical and mental health. ${ }^{56}$ To accurately grasp the mental health status of the elderly, we use one positive question and two negative questions for purposes of measuring subjective mental health.

The psychological health of the elderly was measured by three questions from CGSS. The three questions were closely related to mental state. The first one was a positively oriented question, namely, "Overall, how happy do you think your life is?" The second and third were negatively oriented questions, namely, "In the last 4 weeks, how often have you felt unhappy or depressed?" and "In the last 4 weeks, how often have you felt that the difficulties in life have grown so large that it is impossible to overcome them?" We encoded the first question in a positive direction ("very unhappy" coded as 1, "fairly unhappy" coded as 2, "hard to tell" coded as 3, "fairly happy" coded as 4 , and "very happy" coded as 5). We reverse-coded the second and third questions ("very often" coded as 1, "often" coded as 2, "sometimes" coded as 3, "seldom" coded as 4, and "never" coded as 5). In general, we selected three questions, each with 5 points. The total score of the three questions is $0-15$ points; the higher the score, the better the mental health status.

\section{Independent Variable}

In this study, internet use is the independent variable. In CGSS, respondents were asked about the frequency of internet use, namely, "What was your use of the Internet (including mobile internet) in the past year?" ("never" coded as 1, "seldom" coded as 2, "sometimes" coded as 3 , "often" coded as 4, and "very often" coded as 5). In addition, based on different exercise frequencies, the use of the internet may have different effects on the mental health of the elderly. Therefore, we created an interaction item, which consisted of internet use multiplied by physical exercise. 


\section{Mediating Variable}

Previous studies implied that a higher level of internet use was associated with a higher level of physical exercise. ${ }^{57-}$ 59 Furthermore, studies showed that physical exercise could stimulate dopamine secretion, which was a positive factor for mental health. ${ }^{60,61}$ Based on this evidence, this study hypothesized that internet use may affect mental health by improving physical exercise frequency. To test this hypothesis, physical exercise was used as a moderating factor in this study. In CGSS, respondents were asked about the frequency of physical exercise, namely, "In the past year, do you often take part in physical exercise in your spare time?" ("never" coded as 1, "several times a year or less" coded as 2 , "several times a month" coded as 3, "several times a week" coded as 4 , and "everyday" coded as 5).

\section{Control Variables}

Previous studies indicated that demographic characteristics and socio-economic status would significantly affect the mental health of older adults. ${ }^{62-64}$ Based on the existing literature, gender ("male" coded as 1, "female" coded as 0 ), age (continuous variable), education ("junior high school or above" coded as 1, "below junior high school" coded as 0), income ("RMB 100,000 and above a year" coded as 1, "below RMB 100,000 a year" coded as 0 ), and social class (1-10, with a higher score indicating a higher social class) were selected as control variables.

\section{Statistical Analyses}

According to Grossman's analysis framework, the OLS model was used for regression analysis.

$$
\begin{aligned}
\text { Mental health }_{i}= & \beta_{0}+\beta_{1} \text { Internet Use }_{i} \\
& +\beta_{2} \text { Physical Exercise }_{i} \\
& +\beta_{2} \text { Internet Use }_{i} * \text { Physical exercise }_{i} \\
& +\beta_{4} C V_{i}+\varepsilon_{i}(i=1,2,3 \ldots N)
\end{aligned}
$$

Where $\beta_{0}$ denotes the intercept term, Mental health ${ }_{i}$ stands for the mental health status of the subject i, Physical Exercise $_{i}$ means the frequency of exercise of the subject $\mathrm{i}$, Internet $\mathrm{Use}_{\mathrm{i}}$ * Physical exercise $\mathrm{i}_{\mathrm{i}}$ represents the interaction items of internet use and physical exercise of the subject $i, \mathrm{CV}_{\mathrm{i}}$ indicates control variables of the subject $\mathrm{i}$, and $\varepsilon_{\mathrm{i}}$ is the error term of the subject i. In addition, $\beta_{1}, \beta_{2}$, $\beta_{3}$, and $\beta_{4}$ are all regression coefficients.

In this study, Stata 16.0 software was used to carry out descriptive analysis, OLS regression, sensitivity test, mediating mechanism analysis, and the test for robustness.

\section{Results}

\section{Descriptive Statistics}

Table 1 displays the descriptive statistics of all the variables. The mean of mental health was 11.838 , and the standard deviation was 2.177 , indicating that the mental health status of respondents was good and that there was no large disparity in terms of residents' mental health status. The mean of internet use was 1.738 , which suggests that most older adults seldom used the internet, whereas

Table I Descriptive Statistics

\begin{tabular}{|l|l|l|l|l|l|}
\hline Variable & Mean & SD & Min & Max & N \\
\hline Mental health & 11.838 & 2.177 & 3 & 15 & 1674 \\
\hline Internet use & 1.738 & 1.343 & 1 & 5 & 1674 \\
\hline Physical exercise & 2.468 & 1.712 & $\mathrm{I}$ & 5 & 1674 \\
\hline $\begin{array}{l}\text { Internet use * } \\
\text { Physical exercise }\end{array}$ & 4.912 & 6.170 & $\mathrm{I}$ & 25 & 1674 \\
\hline Gender & 0.492 & 0.500 & 0 & 1 & 1674 \\
\hline Age & 71.573 & 8.042 & 60 & 107 & 1674 \\
\hline Education & 0.484 & 0.500 & 0 & 1 & 1674 \\
\hline Income & 0.060 & 0.237 & 0 & 1 & 1674 \\
\hline Social class & 4.091 & 1.778 & 1 & 10 & 1674 \\
\hline
\end{tabular}

Note: Internet use *Physical exercise means the interaction item of internet use and physical exercise. 
the mean of physical exercise was 2.468 , which shows that most older adults did a medium level of exercise. The standard deviation of internet use multiplied by physical exercise was higher than those of internet use, mental health, and physical exercise, indicating a significant gap within this variable. According to the mean value, we have an almost equal proportion of males and females in our sample. For those respondents aged between 60 and 107 , the mean age was 71.573 years old. In addition, half of the respondents received a junior high school education, and most respondents had a yearly income of less than RMB 100,000 (US \$15,381). Also, most respondents thought they belonged to the lower middle class in society.

\section{The Effect of Internet Use on the Mental Health of Older Adults}

Although China's urban and rural internet users are increasing and the internet penetration rate is increasing year by year, the gap between urban and rural areas is still large. In reality, the urban-rural binary opposition continues to exist and extend in the virtual world, which means the Internet. How to solve the urban-rural digital divide must still be explored. Therefore, considering the huge differences in internet use between urban and rural areas in China, we established three models, using overall samples, urban samples, and rural samples to explore the impact of Internet use on the mental health of the elderly. Among them, the size of the overall sample is 1674, the size of the urban sample is 806 , and the size of the rural sample is 868 .
In this study, three regression models were used to investigate the effects of internet use and control variables on the mental health of the elderly. Model 1 was a fullsample regression. Model 2 was the regression results of the urban elderly as the research object. Model 3 was the regression results of the rural elderly sample.

Table 2 shows that internet use had a significant positive impact on the mental health of the elderly. The regression results of the full sample show that the regression coefficient of the influence of internet use on the mental health of the elderly was 0.114 , which was significant at the $1 \%$ level. This implies that if internet use was increased by 1 , the mental health of the elderly would increase by $11.4 \%$ at the $1 \%$ significance level. Through the examination of the urban sub-sample, internet use also had a significant positive impact on the mental health of urban elderly people at the 5\% level. Specifically, if the use of the internet increased by 1 , the mental health level increased by $10.8 \%$ at the $5 \%$ significance level. However, the impact of internet use on the mental health of rural elderly was not significant. The reason for this difference could be explained by the differences in internet penetration between urban and rural areas in China. In addition, as a control variable, social class showed a constant significant positive impact on the mental health of the elderly for three different sample groups at the $1 \%$ significance level. The higher the level of subjective social class, the better the mental health of the elderly.

Table 2 Results of Global Regression Analysis

\begin{tabular}{|c|c|c|c|}
\hline \multirow[t]{2}{*}{ Variable } & Full Sample & Urban Sample & Rural Sample \\
\hline & Model I & Model 2 & Model 3 \\
\hline Internet use & $\begin{array}{l}0.114^{* * * *} \\
(2.69)\end{array}$ & $\begin{array}{l}0.108 * * \\
(2.18)\end{array}$ & $\begin{array}{l}0.019 \\
(0.18)\end{array}$ \\
\hline Gender & $\begin{array}{l}-0.061 \\
(-0.60)\end{array}$ & $\begin{array}{l}0.067 \\
(0.47)\end{array}$ & $\begin{array}{l}-0.045 \\
(-0.30)\end{array}$ \\
\hline Age & $\begin{array}{l}0.025 * * * \\
(3.95)\end{array}$ & $\begin{array}{l}0.027 * * * \\
(3.02)\end{array}$ & $\begin{array}{l}0.014 \\
(1.42)\end{array}$ \\
\hline Education & $\begin{array}{l}0.632 * * * \\
(5.45)\end{array}$ & $\begin{array}{l}0.250 \\
(1.43)\end{array}$ & $\begin{array}{l}0.604 * * * \\
(3.36)\end{array}$ \\
\hline Income & $\begin{array}{l}0.290 \\
(1.37)\end{array}$ & $\begin{array}{l}0.187 \\
(0.67)\end{array}$ & $\begin{array}{l}0.431 \\
(1.35)\end{array}$ \\
\hline Social class & $\begin{array}{l}0.319 * * * \\
(11.16)\end{array}$ & $\begin{array}{l}0.247 * * * \\
(6.13)\end{array}$ & $\begin{array}{l}0.358 * * * \\
(8.78)\end{array}$ \\
\hline
\end{tabular}

Notes: ${ }^{* * *} \mathrm{p}<0.01,{ }^{* *} \mathrm{p}<0.05$. The values inside the brackets are t-values. 
The Effect of Interaction Items of Internet Use and Physical Exercise on the Mental Health of Older Adults

Table 3 shows the regression result of model 4. Only internet use or physical exercise had no significant effect on the mental health of the elderly. However, when the combination of internet use and physical exercise became an interactive item, this interactive variable had a significant positive impact on the mental health of the elderly at the $1 \%$ level. In addition, the results suggest that as older adults aged, attained higher education levels, and were positioned in higher social classes, they had better mental health status. Considering the obvious difference in whether internet use has a significant impact on the mental health of the elderly, it is worth further studying why the interaction items formed by the combination of internet use and physical exercise had a significant positive impact when they had no significant impact on the mental health of the elderly alone.

Internet use usually affects mental health through two forms of influencing mechanisms. One is using the internet alone to obtain psychological comfort, and thereby improve mental health, and the other is using the internet to promote exercises for the elderly, and thereby improve

Table 3 Regression Results of the Effect of the Combination of Internet Use and Physical Exercise on the Mental Health of the Elderly

\begin{tabular}{|l|l|}
\hline Variable & Model 4 \\
\hline Internet use & $\begin{array}{l}-0.091 \\
(-1.10)\end{array}$ \\
\hline Physical exercise & $\begin{array}{l}0.039 \\
(0.79)\end{array}$ \\
\hline Internet use * Physical exercise & $\begin{array}{l}0.055^{* * *} \\
(2.48)\end{array}$ \\
\hline Gender & -0.050 \\
& $(-0.50)$ \\
\hline Age & $\begin{array}{l}0.025 * * * \\
(3.89)\end{array}$ \\
\hline Education & $\begin{array}{l}0.562^{* * *} \\
(4.80)\end{array}$ \\
\hline Income & $\begin{array}{l}0.255 \\
(1.21)\end{array}$ \\
\hline Social class & $\begin{array}{l}0.304^{* * *} \\
(10.61)\end{array}$ \\
\hline
\end{tabular}

Notes: ${ }^{* * *} \mathrm{p}<0.01$. The values inside the brackets are $\mathrm{t}$-values. Internet use *Physical exercise means the interaction item of internet use and physical exercise. mental health. The results in Table 3 show that the path of internet use directly affecting the mental health of the elderly was not significant. Only when the internet was combined with physical exercise did internet use have a significant positive impact on the mental health of the elderly. Therefore, it is particularly important to explore the intermediary role of physical exercise.

\section{Mediating Effect Analysis}

In previous studies, the mediating effect was generally tested with reference to the causal stepwise regression analysis proposed by Baron and Kenny (1986). ${ }^{65}$ However, in recent years, many scholars have questioned the rationality and effectiveness of this method. Baron and Kenny (1986) believed that complete mediation is the strongest evidence for the existence of mediation effect, and some mediations are not considered to be ideal results. However, Iacobucci et al (2007) pointed out that if the mediation effect is correctly manipulated, most of the mediation effects are partial mediations. ${ }^{66}$ Aiming at many problems existing in Baron and Kenny's (1986) mediation effect test, Zhao et al (2010) summarized and proposed a set of more effective mediation effect test methods and recommended that the mediation test be carried out according to the bootstrap method proposed by Preacher and Hayes (2004). ${ }^{67,68}$ The mediation effect test procedure proposed by Zhao et al (2010) has been widely referred to by scholars all over the world in recent years and has been cited in academic journals in the fields of psychology and gerontology. ${ }^{69}$ We have adopted this mediation effect test method to test whether physical exercise mediates the relationship between internet use and the mental health status of the elderly.

In this section, we attempted to investigate whether internet use influences mental health indirectly by influencing physical exercise. The result is presented in Table 4. The result shows that the total effect of internet use on the mental health of the elderly was statistically significant and positive (effect $=0.114,95 \%$ confidence interval ranges from 0.031 to 0.198$)$. After the introduction of the moderating variable of physical exercise, the direct effect of internet use on the mental health of the elderly was significant (effect $=0.084,95 \%$ confidence interval ranges from 0.004 to 0.163 ). Meanwhile, the indirect effect of internet use on the mental health of the elderly was significant (effect $=0.031,95 \%$ confidence interval ranges from 0.012 to 0.048). Consequently, physical exercise played a mediating role in the relationship between internet use and mental health and the ratio of the indirect effect to 
Table 4 Mediating Role of Physical Exercise Between Internet Use and Mental Health

\begin{tabular}{|l|l|l|l|l|l|}
\hline & Effect & Standard Error & LLCl & ULCI & Ratio \\
\hline Total effect (c) & 0.114 & 0.043 & 0.031 & 0.198 & \\
Direct effect (c') & 0.084 & 0.041 & 0.004 & 0.163 & 0.048 \\
Indirect effect (ab) & 0.031 & 0.009 & 0.012 & & 0.272 \\
Ratio of indirect to total effect mediated & & & & & 0.369 \\
Ratio of indirect to direct effect & & & & \\
\hline
\end{tabular}

Notes: c path represents the total effect of internet use on mental health directly. a path represents the effect of the independent variable of internet use on the intermediary variable of physical exercise. b path represents the effect of the intermediary variable of physical exercise on the dependent variable of mental health, while c' represents the effect of the independent variable of internet use on the dependent variable of mental health after considering or controlling for intermediary variable physical exercise.

Abbreviations: $\mathrm{LLCl}$, lower level for confidence interval; ULCl, upper level for confidence interval.

total effect mediated was 0.272 . It is important to note that the size of the indirect effect through physical exercise was quite large, and the effect was statistically significant.

\section{The Heterogeneity of the Psychological Effects of Internet Use Among Older Adults}

In the previous work, the average effect of internet use on the mental health of elderly people was obtained by treating all elderly people as homogenous groups. In fact, there is a certain heterogeneity in internet use among elderly groups with different individual characteristics. Based on previous results, social class was the only control variable that had a significant impact on three different sample groups (total sample, urban sub-sample, and rural sub-sample). Therefore, we chose social class to carry out the heterogeneity analysis. Table 5 shows that in model 5 , the interaction item of internet use and social class had a significant negative impact on the mental health of the elderly, which indicated that with the increase in the subjective social class level, internet use would have a negative impact on mental health. This might be explained by the fact that, as people positioned in a higher social class, they might use the internet for work rather than for entertainment; therefore, a high frequency of internet use could be a burden to their mental health status.

\section{Robustness Test}

The robustness test examines the robustness of the interpretation ability of the evaluation methods and indicators, that is, whether the evaluation methods and indicators maintain a relatively consistent and stable interpretation of the evaluation results when some parameters are changed. In short, when we draw a conclusion, we must verify whether that conclusion is reliable through a series of methods. When we
Table 5 Regression Results of the Heterogeneity of the Psychological Effects of Internet Use on Older Adults

\begin{tabular}{|l|l|}
\hline Variable & Model 5 \\
\hline Internet use & $\begin{array}{l}0.318^{* * * *} \\
(3.22)\end{array}$ \\
\hline Internet use * Social class & $\begin{array}{l}-0.470^{* *} \\
(-2.28)\end{array}$ \\
\hline Gender & $\begin{array}{l}-0.049 \\
(-0.48)\end{array}$ \\
\hline Age & $\begin{array}{l}0.025 * * * \\
(3.93)\end{array}$ \\
\hline Education & $\begin{array}{l}0.620 * * * \\
(5.35)\end{array}$ \\
\hline Income & $\begin{array}{l}0.332 \\
(1.57)\end{array}$ \\
\hline Social class & $\begin{array}{l}0.404 * * * \\
(8.64)\end{array}$ \\
\hline
\end{tabular}

Notes: $* * * p<0.01, * * p<0.05$. The values inside the brackets are $t$-values.

change some conditions or assumptions and find that the conclusion remains unchanged, our conclusion is robust. On the other hand, the conclusion remains to be discussed. We must discover the reasons for the change in the conclusion and explain it. At present, there is no unified standard for robustness testing, and there is no clear explanation to tell us from which angles we should conduct robustness testing in the article. Therefore, according to different research purposes, the perspective of the robustness test will vary. According to the previous studies, the commonly used angles of the robustness test include the variable replacement method, changing sample size method, sub-sample regression method, supplementary variable method, and so on. In the empirical paper writing analysis, the variable replacement method aims mainly at the dependent variables 
(explained variables) and independent variables (explanatory variables) of the investigated topic. According to the measurement methods in different literature, a study can cite different measurement methods of dependent (independent) variables to investigate the robustness of research problems or research hypotheses. Of course, this also reflects the researcher's prudence and rationality in writing.

Considering that our dependent variable was composed of three questions reflecting the degree of mental health, including whether the interviewee felt happy, whether the interviewee was occasionally depressed, and whether the interviewee experienced many difficulties in life, we did not use the question directly reflecting the degree of mental health. Because depression is a direct indicator of mental health, we used this question to replace our dependent variable to reflect mental health when replacing the variable to test the robustness.

Considering the possible existence of "selection bias" endogenous problems in our models, to verify whether the influence of internet use on the mental health of the elderly was consistent and stable, this study used a new variable ("In the past 4 weeks, how often have you felt depressed?", "always" coded as 1, "often" coded as 2, "sometimes" coded as 3, "seldom" coded as 4, and "never" coded as 5) to represent the mental health status as a dependent variable, then ran a sensitivity analysis. The results were consistent with previous regression models, so our results were robust.

Table 6 shows that after we used a substitute dependent variable to represent the mental health of the elderly, internet use still had a significant positive impact on the mental health of the elderly. The regression results of the full sample show that the regression coefficient of the influence of internet use on the mental health of the elderly was 0.057 , which was significant at the $1 \%$ level. This implies that if internet use increased by 1 , the mental health of the elderly would increase by $5.7 \%$ at the $1 \%$ significance level. Examination of the urban sub-sample revealed that internet use also had a significant positive impact on the mental health of urban elderly people at the $5 \%$ level. Specifically, if the use of the internet increased by 1 , the mental health level increased by $5.1 \%$ at the $5 \%$ significance level. However, the impact of internet use on the mental health of the rural elderly was not significant. The reason for this difference could be explained by the differences in internet penetration between urban and rural areas in China. In addition, as a control variable, social class showed a constant significant positive impact on the mental health of the elderly for three different sample groups
Table 6 Results of Sensitivity Analysis

\begin{tabular}{|l|l|l|l|}
\hline \multirow{2}{*}{ Variable } & Full Sample & Urban Sample & Rural Sample \\
\cline { 2 - 4 } & Model 9 & Model I0 & Model I I \\
\hline Internet use & $\begin{array}{l}0.057 * * * \\
(2.75)\end{array}$ & $\begin{array}{l}0.05 I^{* *} \\
(2.02)\end{array}$ & $\begin{array}{l}-0.040 \\
(-0.84)\end{array}$ \\
\hline Gender & $0.084^{*}$ & $0.172^{* *}$ & 0.075 \\
& $(1.68)$ & $(2.36)$ & $(1.09)$ \\
\hline Age & 0.002 & -0.001 & -0.003 \\
& $(0.49)$ & $(-0.11)$ & $(-0.66)$ \\
\hline Education & $0.243 * * *$ & 0.037 & $0.213^{* *}$ \\
& $(4.28)$ & $(0.4 I)$ & $(2.52)$ \\
\hline Income & 0.111 & 0.122 & 0.078 \\
& $(1.07)$ & $(0.85)$ & $(0.52)$ \\
\hline Social class & $0.110^{* * *}$ & $0.092 * * *$ & $0.112^{* * *}$ \\
& $(7.88)$ & $(4.44)$ & $(5.87)$ \\
\hline
\end{tabular}

Notes: $* * *^{*}<0.01, *{ }^{*} p<0.05,{ }^{*}<<0.1$. The values inside the brackets are $t$-values.

at the $1 \%$ significance level. The higher the level of subjective social class, the better the mental health of the elderly.

\section{Discussion, Conclusion, and Recommendations}

Using the survey data of the CGSS (2017) and OLS regression model, this paper comprehensively investigated the influence mechanism of internet use on the mental health of the elderly by analyzing the mediating effect, discussed the heterogeneity of the impact of internet use on the mental health of the elderly, and carried out the robustness test. Based on existing studies, ${ }^{70,71}$ this study made progress in terms of research questions and research perspectives: (1) This study not only investigated the effects of internet use on the mental health of the elderly, but also introduced physical exercise as a mediating variable to analyze the impact mechanism. (2) This study compared urban-rural internet use disparity and found that due to unbalanced internet penetration, this mechanism was very different in urban and rural areas. This is consistent with the conclusion confirmed by many studies, that is, many intermediary mechanisms - such as social capital, internet application capability, internet accessibility, income level, social class, family support, and other factors - promote the mental health of the elderly in the internet environment, though these are indirect factors, which do not easily affect mental health. Only strengthening exercise for the elderly in the internet 
environment can directly improve the mental health of the elderly through internal physical health adjustment. This is because more studies are recognizing that exercise has a positive impact on emotional states such as anxiety, stress, and depression through physiological and biochemical mechanisms. ${ }^{72}$ This also shows that exercise is credible as an intermediary mechanism to explain that the internet promotes the mental health of the elderly.

Through empirical analysis, this paper drew the following conclusions: (1) Internet use could significantly improve the mental health of the elderly. In addition, by dividing samples into urban and rural areas, this study found that internet use had a significant impact on the mental health of urban elderly people at the $5 \%$ level, while the impact on the mental health of rural elderly people was not significant. (2) Internet use was a path to improve the mental health of the elderly through the partial mediating effect. (3) The heterogeneity of internet use on the mental health of the elderly was investigated. The results showed that with higher subjective social class levels, internet use negatively impacted mental health.

According to Grossman's health theory, to maintain an inherently healthy capital stock or to slow its depletion, it is necessary to invest in the factors that produce health. ${ }^{73}$ Many studies began to regard internet use as technological capital to promote the mental health of the elderly, emphasizing that internet investment to improve the health of the elderly is an important proposition in national health governance. ${ }^{74-76}$ However, many studies ignored the fact that internet use alone could not improve the mental health status of the elderly. There existed two kinds of mechanisms. One was that by using the internet, the elderly received psychological help, which improved their mental health. ${ }^{77,78}$ The other was that internet use made a positive impact on mental health in combination with offline factors such as exercise and friend interactions. ${ }^{79,80}$ Unlike studies focusing on offline factors such as social capital, this study based its research question on recent Chinese public health policy, which called on the elderly to participate in more exercises by using the internet; this study aimed to find the scientific mechanism underlying this public health policy.

Several limitations of this study should be acknowledged. First, given that the data used in this study was collected in 2017, it may be difficult to reflect the latest situation. Second, we explored only the correlation, rather than the causality, due to the cross-sectional design. Third, due to limitations of the data, both dependent and independent variables were subjective data; therefore, further studies should use objective data if this is available.

To the best of our knowledge, this is the first study to examine the mediating effect of physical exercise on the relationship between internet use and mental health among Chinese older adults.

With the promotion and implementation of the "Internet Plus Exercise" health governance strategy, internet use will play a greater role in health management, and the elderly group cannot be excluded. In fact, as an expanding group, the popularity of the internet will have a significant impact on the mental health of older people. Therefore, based on the above research conclusions, this study makes the following policy recommendations: (1) Improve the popularity of the internet among the elderly. On the one hand, in the context of internet health governance, we should strengthen the infrastructure of the internet network, increasing opportunities for the elderly to obtain access to the internet, especially for the elderly in rural areas. On the other hand, the biggest problem for the elderly with regarding to using the internet to improve their mental health is that they do not combine internet use with physical exercise; therefore, more offline exercise options should be provided to help the elderly master exercising through internet use. (2) In view of the heterogeneity of the impact of internet use on the mental health of the elderly, the elderly should be treated differently to achieve accurate support while improving their internet usage. The elderly of different social classes should carefully assess whether internet use will improve their exercise frequency, and thereby decide whether it is an applicable mechanism for their personalized situations.

Our findings suggest that internet use was significantly associated with a better mental health status for older Chinese residents, mediated by higher physical exercise frequency, which is consistent with China's recent efforts to promote health governance through the "Internet Plus Exercise" strategy and provide public health policy implications for other countries globally.

\section{Acknowledgment}

The authors would like to acknowledge the Chinese General Social Survey (CGSS) team for providing data. Because the present study was conducted based on the deidentified, publicly available CGSS data, it does not constitute human subject research. Its institutional review board review was waived because there was no interaction with any individual, and no identifiable private information was used. 


\section{Author Contributions}

Conceptualization: Sheng Zhang; data curation: Yujie Zhang; formal analysis: Yujie Zhang; funding acquisition: Sheng Zhang and Yujie Zhang; methodology: Yujie Zhang; software: Yujie Zhang; supervision: Sheng Zhang; writing - original draft: Sheng Zhang and Yujie Zhang; writing - review and editing: Sheng Zhang and Yujie Zhang. All authors contributed to data analysis, drafting the article, or revising the article, have agreed on the journal to which the article will be submitted, gave final approval of the version to be published, and agree to be accountable for all aspects of the work.

\section{Funding}

This study was supported by the National Social Science Foundation of China (20\&ZD182).

\section{Disclosure}

The authors declare that they have no conflicts of interest.

\section{References}

1. Knight BG, Sayegh P. Mental health and aging in the 21st century. $J$ Aging Soc Policy. 2011;23(3):228-243. doi:10.1080/ 08959420.2011.579494

2. Aggarwal B, Xiong Q, Schroeder-Butterfill E. Impact of the use of the internet on quality of life in older adults: review of literature. Prim Health Care Res Dev. 2020;21(e55):1-6. doi:10.1017/ $\mathrm{S} 1463423620000584$

3. Lai CKY, Arthur DG, Chau WWH. Implication of internet growth on enhancing health of disadvantaged groups in China: a global perspective. J Clin Nurs. 2004;13(6B):68-73. doi:10.1111/j.13652702.2004.01046.x

4. Guo L. WeChat as a semipublic alternative sphere: exploring the use of WeChat among Chinese older adults. Int J Commun. 2017;11 (1):408-428.

5. Pan S. Examining the effects of social networks formed in a seniororiented online community on older participants' subjective wellbeing in China. Chin J Commun. 2018;11(2):135-154. doi:10.1080/ 17544750.2017.1296012

6. Yuan H. Internet use and mental health problems among older people in Shanghai, China: the moderating roles of chronic diseases and household income. Aging Ment Health. 2021;25(4):657-663. doi:10.1080/13607863.2020.1711858

7. Grossman M. On the concept of health capital and the demand for health. J Polit Econ. 1972;80(2):223-255. doi:10.1086/259880

8. Grossman M. The human capital model. In: Culyer AJ, Newhouse JP, editors. Handbook of Health Economics. Elsevier Science, Amsterdam, AMS; 2000:347-408.

9. Liljas B. The demand for health with uncertainty and insurance. $J$ Health Econ. 1998;17(2):153-170. doi:10.1016/S0167-6296(97) 00021-0

10. Leibowitz AA. The demand for health and health concerns after 30 years. $J$ Health Econ. 2004;23(4):663-671. doi:10.1016/j. jhealeco.2004.04.005

11. Zweifel P. The Grossman model after 40 years. Eur J Health Econ. 2012;13(6):677-682. doi:10.1007/s10198-012-0420-9
12. Monheit AC, Grafova IB. Education and family health care spending. South Econ J. 2018;85(1):71-92. doi:10.1002/soej.12300

13. Hartwig J, Sturm JE. Testing the Grossman model of medical spending determinants with macroeconomic panel data. Eur J Health Econ. 2018;19(8):1067-1086. doi:10.1007/s10198-018-0958-2

14. Corman H, Dave D, Reichman NE. Evolution of the infant health production function. South Econ J. 2018;85(1):6-47. doi:10.1002/ soej. 12279

15. Chen YW, Persson A. Internet use among young and older adults: relation to psychological wellbeing. Educ Gerontol. 2002;28 (9):731-744. doi:10.1080/03601270290099921

16. Noel JG, Epstein J. Social support and health among senior Internet users: results of an online survey. J Technol Human Serv. 2003;21 (3):35-54. doi:10.1300/J017v21n03 03

17. Dorin M. Online education of older adults and its relation to life satisfaction. Educ Gerontol. 2007;33(2):127-143. doi:10.1080/ 03601270600850776

18. Lam L, Lam M. The use of information technology and mental health among older care-givers in Australia. Aging Ment Health. 2009;13 (4):557-562. doi:10.1080/13607860802607306

19. Hernandez-Encuentra E, Pousada M, Gomez-Zuniga B. ICT and older adults: beyond usability. Educ Gerontol. 2009;35(3):226-245. doi:10.1080/03601270802466934

20. Goodall K, Ward P, Newman L. Use of information and communication technology to provide health information: what do older migrants know, and what do they need to know? Qual Prim Care. 2010;18(1):27-32.

21. Sum S, Mathews RM, Hughes I. Participation of older adults in cyberspace: how Australian older adults use the internet. Australas. Ageing. 2009;28(4):189-193.

22. Cangelosi PR, Sorrell JM. Use of technology to enhance mental health for older adults. J Psychosoc Nurs Ment Health Serv. 2014;52(9):17-20. doi:10.3928/02793695-20140721-01

23. Handley T, Perkins D, Kay-Lambkin F, Lewin T, Kelly B. Familiarity with and intentions to use Internet-delivered mental health treatments among older rural adults. Aging Ment Health. 2015;19(11):989-996. doi:10.1080/13607863.2014.981744

24. Hunsaker A, Hargittai E, Piper AM. Online social connectedness and anxiety among older adults. Int J Commun. 2020;14(1):697-725.

25. Leszko M. The role of online communication among spousal caregivers of individuals with Alzheimer's disease. J Women Aging. 2020;32(4):462-480. doi:10.1080/08952841.2020.1754119

26. Karavidas M, Lim NK, Katsikas SL. The effects of computers on older adult users. Comput Hum Behav. 2005;21(5):697-711. doi:10.1016/j.chb.2004.03.012

27. Firth L, Mellor D. Dilettantism in investigating the impact of the Internet on the wellbeing of the older adults. Qual Quant. 2009;43 (2):185-196. doi:10.1007/s11135-007-9108-0

28. Cotten SR, Ford G, Ford S, Hale TM. Internet use and depression among retired older adults in the United States: a Longitudinal analysis. J Gerontol Ser B Psychol Sci Soc Sci. 2014;69(5):763-771.

29. Chang J, Mcallister C, Mccaslin R. Correlates of, and barriers to, internet use among older adults. J Gerontol Soc Work. 2015;58 (1):66-85. doi:10.1080/01634372.2014.913754

30. Forsman AK, Nordmyr J. Psychosocial links between internet use and mental health in later life: a systematic review of quantitative and qualitative evidence. $J$ Appl Gerontol. 2017;36(12):1471-1518. doi:10.1177/0733464815595509

31. Jun HJ, Kim MY. What accounts for the relationship between internet use and suicidal ideation of Korean older adults? A mediation analysis. J Gerontol Ser B Psychol Sci Soc Sci. 2017;72(5):846-855.

32. Forsman AK, Nordmyr J, Matosevic T, Park AL, Wahlbeck K, McDaid D. Promoting mental wellbeing among older people: technology-based interventions. Health Promot Int. 2018;33 (6):1042-1054. doi:10.1093/heapro/dax047 
33. Hunsaker A, Hargittai E. A review of Internet use among older adults. New Media Soc. 2018;20(10):3937-3954. doi:10.1177/ 1461444818787348

34. Liao SM, Zhou YJ, Liu YF, Wang RX. Variety, frequency, and type of internet use and its association with risk of depression in middleand older -aged Chinese: a cross-sectional study. J Affect Disord. 2020;273(5):280-290. doi:10.1016/j.jad.2020.04.022

35. Lyu SJ, Sun J. Internet use and self-rated health among Chinese older adults: the mediating role of social capital. Geriatr Gerontol Int. 2020;21(1):34-38. doi:10.1111/ggi.14090

36. Zhu Y, Zhou Y, Long C, et al. The relationship between internet use and health among older adults in China: the mediating role of social capital. Healthcare. 2021;9(5):559. doi:10.3390/healthcare9050559

37. Sharit J, Hernandez MA, Czaja SJ, Pirolli P. Investigating the roles of knowledge and cognitive abilities in older adult information seeking on the Web. ACM Trans Comput Hum Interact. 2008;15(1):3. doi: $10.1145 / 1352782.1352785$

38. Cavender AC, Bigham JP. Toward web accessibility for older users. Univers Access Inf Soc. 2011;10(4):357-358. doi:10.1007/s10209011-0219-y

39. Chekroud SR, Gueorguieva R, Zheutlin AB, et al. Association between physical exercise and mental health in 1.2 million individuals in the USA between 2011 and 2015: a cross-sectional study. Lancet Psychiatry. 2018;5(9):739-746. doi:10.1016/S2215-0366(18)30227-X

40. Ihm J, Hsieh YP. The implications of information and communication technology use for the social well-being of older adults. Info Commun Soc. 2015;18(10):1123-1138. doi:10.1080/ 1369118X.2015.1019912

41. Xiong J, Zuo M. How does family support work when older adults obtain information from mobile internet? Inf Technol People. 2019;32 (6):1496-1516. doi:10.1108/ITP-02-2018-0060

42. Keane MC, Roeger LS, Allison S, Reed RL. E-mental health in South Australia: impact of age, gender and region of residence. Aust J Prim Health. 2013;19(4):331-335. doi:10.1071/PY13027

43. Chang SJ, Im EO. A path analysis of internet health information seeking behaviors among older adults. Geriatr Nurs. 2014;35 (2):137-141. doi:10.1016/j.gerinurse.2013.11.005

44. Booth AO, Nowson CA, Matters H. Evaluation of an interactive, Internet-based weight loss program: a pilot study. Health Educ Res. 2008;23(3):371-381. doi:10.1093/her/cyn007

45. Tomita MR. Improving adherence to exercise in patients with heart failure through internet-based self-management. $J$ Am Geriatr Soc. 2008;56(10):1981-1983. doi:10.1111/j.1532-5415.2008.01865.x

46. Geraghty AWA, Stanford R, Stuart B, et al. Using an Internet intervention to support self-management of low back pain in primary care: findings from a randomised controlled feasibility. BMJ Open. 2018;8 (3):e016768. doi:10.1136/bmjopen-2017-016768

47. Wang ZH, Kiryu T, Iwaki M, Shibai K. An Internet-based cycle ergometer health promotion system for providing personally fitted exercise. IEICE Trans Inf Syst. 2005;E88D(8):1985-1992. doi:10.1093/ietisy/e88-d.8.1985

48. Elliot AJ, Mooney CJ, Douthit KZ, Lynch MF. Predictors of older adults' technology use and its relationship to depressive symptoms and well-being. J Gerontol Ser B Psychol Sci Soc Sci. 2014;69 (5):667-677.

49. Linley PA, Maltby J, Wood AM, et al. Measuring happiness: the higher order factor structure of subjective and psychological well-being measures. Pers Individ Differ. 2009;47(8):878-884. doi:10.1016/j.paid.2009.07.010

50. Walsh R. Lifestyle and mental health. Am Psychol. 2011;66(7):579. doi:10.1037/a0021769

51. Galderisi S, Heinz A, Kastrup M, et al. Toward a new definition of mental health. World Psychiatry. 2015;14(2):231. doi:10.1002/wps.20231

52. Mollica RF, Cardozo BL, Osofsky HJ, et al. Mental health in complex emergencies. Lancet. 2004;364(9450):2058-2067. doi:10.1016/ S0140-6736(04)17519-3
53. Sisask M, Värnik A, Kolves K, et al. Subjective psychological well-being (WHO-5) in assessment of the severity of suicide attempt. Nord J Psychiatr. 2008;62(6):431-435. doi:10.1080/ 08039480801959273

54. Kafka GJ, Kozma A. The construct validity of Ryff's scales of psychological well-being (SPWB) and their relationship to measures of subjective well-being. Soc Indic Res. 2002;57(2):171-190. doi:10.1023/A:1014451725204

55. Joshanloo $M$. Investigating the relationships between subjective well-being and psychological well-being over two decades. Emotion. 2019;19(1):183. doi:10.1037/emo0000414

56. Hanley A, Warner A, Garland EL. Associations between mindfulness, psychological well-being, and subjective well-being with respect to contemplative practice. J Happiness Stud. 2015;16 (6):1423-1436. doi:10.1007/s10902-014-9569-5

57. Ting J, Chien KP, Dhir A, et al. Sports interest mediating exercise and compulsive internet use among undergraduates. Health Promot Int. 2019;34(5):953-960. doi:10.1093/heapro/day046

58. Lin L, Liu J, Cao X, et al. Internet addiction mediates the association between cyber victimization and psychological and physical symptoms: moderation by physical exercise. BMC Psychiatry. 2020;20 (1):1-8. doi:10.1186/s12888-020-02548-6

59. Tate DF, Lyons EJ, Valle CG. High-tech tools for exercise motivation: use and role of technologies such as the internet, mobile applications, social media, and video games. Diabetes Spectrum. 2015;28 (1):45-54. doi:10.2337/diaspect.28.1.45

60. Raglin JS. Exercise and mental health. Sports Med. 1990;9 (6):323-329. doi:10.2165/00007256-199009060-00001

61. Grasdalsmoen M, Eriksen HR, Lønning KJ, et al. Physical exercise, mental health problems, and suicide attempts in university students. BMC Psychiatry. 2020;20(1):1-11. doi:10.1186/s12888-020-02583-3

62. German PS, Shapiro S, Skinner EA. Mental health of the elderly: use of health and mental health services. J Am Geriatr Soc. 1985;33 (4):246-252. doi:10.1111/j.1532-5415.1985.tb07111.x

63. Levkoff SE, Macarthur IW, Bucknall J. Elderly mental health in the developing world. Soc Sci Med. 1995;41(7):983-1003. doi:10.1016/ 0277-9536(94)00434-U

64. Gurland BJ. The Mind and Mood of Aging: Mental Health Problems of the Community Elderly in New York and London. London, Lon: Psychology Press; 1983.

65. Baron RM, Kenny DA. The moderator-mediator variable distinction in social psychological research: conceptual, strategic, and statistical considerations. J Pers Soc Psychol. 1986;51(6):1173. doi:10.1037/ 0022-3514.51.6.1173

66. Iacobucci D, Saldanha N, Deng X. A meditation on mediation: evidence that structural equations models perform better than regressions. J Consum Psychol. 2007;17(2):139-153. doi:10.1016/ S1057-7408(07)70020-7

67. Zhao X, Lynch JG, Chen Q. Reconsidering Baron and Kenny: myths and truths about mediation analysis. J Consum Res. 2010;37 (2):197-206. doi:10.1086/651257

68. Preacher KJ, Hayes AF. SAS procedures for estimating indirect effects in simple mediation models. Behav Res Methods Instrum Comput. 2004;36(4):717-731. doi:10.3758/BF03206553

69. Lyu S, Sun J. Internet use and self-rated health among Chinese older adults: the mediating role of social capital. Geriatr Gerontol Int. 2021;21(1):34-38

70. Mailey EL, Wójcicki TR, Motl RW, et al. Internet-delivered physical activity intervention for college students with mental health disorders: a randomized pilot trial. Psychol Health Med. 2010;15 (6):646-659. doi:10.1080/13548506.2010.498894

71. Irvine AB, Gelatt VA, Seeley JR, et al. Web-based intervention to promote physical activity by sedentary older adults: randomized controlled trial. J Med Internet Res. 2013;15(2):e19. doi:10.2196/ jmir.2158 
72. Mikkelsen K, Stojanovska L, Polenakovic M. Exercise and mental health. Maturitas. 2017;106:48-56. doi:10.1016/j.maturitas.2017.09.003

73. Grossman M. The Demand for Health. New York, NY: Columbia University Press; 2017.

74. Ybarra ML, Eaton WW. Internet-based mental health interventions. Ment Health Serv Res. 2005;7(2):75-87. doi:10.1007/s11020-0053779-8

75. Bianchi C. Exploring how internet services can enhance elderly well-being. J Serv Mark. 2021;35(2):2-19. doi:10.1108/JSM-052020-0177

76. Shah A. The relationship between elderly suicide rates and the internet: a cross-national study. Int J Soc Psychiatr. 2010;56(3):214-219. doi:10.1177/0020764009105645

77. Ahn JH, Lim KC, Lee YJ, et al. Effects of computer/internet game play on depression and life satisfaction among the elderly: mediating effects of perceived self-control. J Korea Contents Assoc. 2011;11 (7):406-417. doi:10.5392/JKCA.2011.11.7.406
78. Sum S, Mathews RM, Pourghasem M, et al. Internet technology and social capital: how the Internet affects seniors' social capital and wellbeing. $J$ Comput -Mediat Commun. 2008;14(1):202-220. doi:10.1111/j.1083-6101.2008.01437.x

79. Marsch LA, Hegel MT, Greene MA. Leveraging digital technology to intervene on personality processes to promote healthy aging. Personal Disord. 2019;10(1):33-45. doi:10.1037/per0000275

80. Kobayashi LC, Wardle J, Wagner CV. Internet use, social engagement and health literacy decline during ageing in a longitudinal cohort of older English adults. J Epidemiol Community Health. 2015;69(3):278-283. doi:10.1136/jech-2014-204733
Risk Management and Healthcare Policy

\section{Publish your work in this journal}

Risk Management and Healthcare Policy is an international, peerreviewed, open access journal focusing on all aspects of public health, policy, and preventative measures to promote good health and improve morbidity and mortality in the population. The journal welcomes submitted papers covering original research, basic science, clinical \& epidemiological studies, reviews and evaluations,
Dovepress

guidelines, expert opinion and commentary, case reports and extended reports. The manuscript management system is completely online and includes a very quick and fair peer-review system, which is all easy to use. Visit http://www.dovepress.com/testimonials.php to read real quotes from published authors. 